\title{
Topical amethocaine gel in the newborn infant: how soon does it work and how long does it last?
}

\author{
A Jain, $\mathrm{N}$ Rutter
}

\begin{abstract}
Aim-To explore the time of onset and duration of action of topical amethocaine gel in the newborn infant.

Design-A randomised double blind placebo controlled trial.

Subjects-Thirty six infants were studied after 30 minutes application and 36 after 60 minutes application. A total of 56 infants (gestation 27-42 weeks, weight $0.79-4.1 \mathrm{~kg}$ ) were studied in the first two weeks after delivery.

Method-1.5 g amethocaine or placebo was applied to the dorsum of either foot, occluded, and then left for 30 or 60 minutes. Local anaesthesia was assessed by observing the cutaneous withdrawal response to graded nylon filaments (von Frey hairs). If there was a difference between feet in filament thickness required to elicit a response, the infant was studied in an identical manner at hourly intervals until the difference had disappeared.

Results-Evidence of local anaesthetic action of amethocaine was seen in 23 of 36 $(64 \%)$ infants after 30 minutes and 26 of 36 $(72 \%)$ infants after 60 minutes application (no significant difference). Evidence of local anaesthetic action was independent of gestation and order of testing. Amethocaine responders showed a significantly deeper anaesthetic action than placebo responders. The median duration of action was 1.5 hours (range 0.5-3.5) after 30 minutes and three hours (range 1-5) after 60 minutes $(p<0.001)$.

Conclusion-Topical amethocaine gel has a local anaesthetic action after $\mathbf{3 0}$ minutes application, but application for $\mathbf{6 0}$ minutes results in longer duration of action.
\end{abstract}

(Arch Dis Child Fetal Neonatal Ed 2000;83:F211-F214)

Keywords: anaesthesia; amethocaine; pain

Painful and invasive procedures are commonly performed in the newborn, particularly in neonatal intensive care units. Heel prick blood sampling and venepuncture are the commonest procedures that pierce the skin and are necessary for the routine care of healthy term and sick premature infants alike. ${ }^{1}$ Venepuncture is probably less painful than unmodified heel lancing, ${ }^{23}$ and the pain can be further reduced by non-pharmacological means. ${ }^{4-6}$ Nevertheless, it is still a painful procedure. Topical local anaesthetics are effective and widely used to relieve the pain of venepuncture in children, but their use in the newborn has been less successful.

The ideal topical local anaesthetic should be quick acting, effective, safe, and should not interfere with the procedure involved. Studies on lignocaine and lignocaine/prilocaine eutectic mixture (EMLA) in the newborn have been disappointing. ${ }^{7-12}$ Amethocaine is an alternative. It is a local anaesthetic of the ester group, available as a $4 \%(\mathrm{w} / \mathrm{w})$ topical gel, which has been shown to provide effective and safe surface local anaesthesia in children. ${ }^{13-16}$

We have recently shown that topical amethocaine gel has a local anaesthetic action on the newborn skin after application for one hour. ${ }^{17}$ Two further pieces of information would be useful before examining amethocaine gel in a clinical setting: the time to onset and the duration of action. We therefore designed a study to answer the following questions: does topical amethocaine gel have a local anaesthetic action when applied for 30 minutes, and, if so, how does this compare with the action after 60 minutes application? If a local anaesthetic action can been shown, how long does it last?

\section{Methods}

We conducted a randomised double blind controlled trial comparing 4\% (w/w) amethocaine gel (Ametop, Smith and Nephew, Hull, UK) with placebo. Surface local anaesthesia was assessed by eliciting the cutaneous withdrawal reflex in response to stimulation of the dorsum of the foot. To provide a range of stimuli, we used a series of 20 graded nylon filaments, von Frey hairs. Each hair consists of a flexible nylon filament attached at right angles to one end of a perspex holder. Each filament has a different thickness, ranging from very fine to thick. The nylon filament is placed on to the dorsum of the foot and deformed by downward pressure. A measurable and reproducible weight is required to deform the filament. When the stimulus exceeds the threshold of the reflex, the cutaneous withdrawal reflex is elicited. This reflex consists of fanning of the toes, followed by flexion of the ankle, knee, and hip and withdrawal of the leg.

We applied a marker ring to the dorsum of each foot. This defined and exposed a circular area of skin $1 \mathrm{~cm}$ in diameter that was used for testing. Within the marker ring, we applied 1.5 g $4 \%(\mathrm{w} / \mathrm{w})$ amethocaine gel to one foot and $1.5 \mathrm{~g}$ placebo to the other foot. The placebo was identical in every way except for the absence of amethocaine. We covered each foot with an occlusive dressing and left the baby alone. The occlusive dressings were removed and the excess gel wiped from each foot after 
either 30 minutes or 60 minutes. The foot to be tested first (left or right foot) and the order of testing (amethocaine/placebo or placebo/ amethocaine) were determined by randomisation in order to control for habituation to repeated stimulation which we had noted previously. ${ }^{17}$

Filament thickness was increased until the cutaneous withdrawal reflex was elicited from the first foot. The filament thickness and its corresponding deforming weight were recorded. This was repeated in an identical fashion on the second foot until the reflex was again elicited. The thickness of filament and corresponding deforming weight required to elicit the reflex were recorded. If there was no difference, the baby was not studied again. Otherwise the baby was studied in an identical manner at one hourly intervals until the difference disappeared. A difference in thickness of filament required to elicit the cutaneous withdrawal reflex from the two feet was taken as evidence of a local anaesthetic action. The difference in corresponding deforming weights was used as a measure of the strength of this action. The duration of action was recorded as the time from application of the gels to the last time when a local anaesthetic action could still be shown.

SUBJECTS

We studied 36 infants after amethocaine and placebo had been applied for 30 minutes and 36 after the gels had been applied for $60 \mathrm{~min}$ utes (table 1). Subjects were studied in the first two weeks after birth by a single observer. In total, we studied 56 babies; 16 were studied twice, the two investigations being a week apart. In each study, subjects were stratified by gestation into three groups of 12: term ( $>37$ weeks), mildly preterm (33-36 weeks), and moderately preterm ( $<32$ weeks). Infants on the neonatal intensive care unit or postnatal wards at Nottingham City Hospital were eligible for entry, but we excluded those who were unwell, ventilated, or sedated. The study was approved by the hospital research ethics committee. Infants were studied with the informed written consent of one or both parents. We obtained exemption from the restrictions of the drug's product licence from the Medicines Control Agency.

Table 1 Details of infants to whom amethocaine was applied for either 30 or 60 minutes

\begin{tabular}{llll}
\hline & 30 minutes & 60 minutes & $p$ Value \\
\hline Gestation (weeks) & $33.5(27-40)$ & $34(27-42)$ & 0.85 \\
Birth weight $(\mathrm{g})$ & $2.01(0.79-4.1)$ & $1.9(0.79-3.93)$ & 0.95 \\
\hline
\end{tabular}

Values are median (range). $p$ Value calculated using the Mann-Whitney $U$ test.

Table 2 Evidence of local anaesthetic action of amethocaine after 30 or 60 minutes application

\begin{tabular}{lllll}
\hline & $\begin{array}{l}\text { Amethocaine } \\
\text { responders }\end{array}$ & $\begin{array}{l}\text { Placebo } \\
\text { responders }\end{array}$ & $\begin{array}{l}\text { Non- } \\
\text { responders }\end{array}$ & p Value \\
\hline 30 minutes application & $23 / 36(64)$ & $6 / 36(17)$ & $7 / 36(19)$ & $<0.001$ \\
60 minutes application & $26 / 36(72)$ & $8 / 36(22)$ & $2 / 36(2)$ & $<0.001$ \\
\hline
\end{tabular}

Values in parentheses are percentages. The p values are for the results of amethocaine $v$ all others.
RANDOMISATION

Placebo and amethocaine were packaged into identical tubes by the hospital pharmacy who randomised and coded them. Packages and codes for the studies of 30 minutes or $60 \mathrm{~min}$ utes application were generated independently. The codes were kept in the pharmacy and broken on completion of the study. Within each gestational age group, infants were assigned to one of four equal groups:

(1) amethocaine applied to right foot, placebo applied to left foot; right foot tested first;

(2) amethocaine applied to right foot, placebo applied to left foot; left foot tested first;

(3) placebo applied to right foot, amethocaine applied to left foot; right foot tested first;

(4) placebo applied to right foot, amethocaine applied to left foot; left foot tested first.

\section{STATISTICAL ANALYSIS}

Statistical analysis was performed using SPSS 8.0 software. The data were not normally distributed and therefore non-parametric statistical tests were used. Comparison of the median von Frey hair thickness in each group and the proportions within the amethocaine and placebo groups who showed a local anaesthetic action were made by Mann-Whitney U and Wilcoxon signed ranked tests respectively. Intergroup differences were tested using the Kruskall-Wallis test. The difference in mean deforming weight required to elicit the reflex from the amethocaine and placebo groups and the duration of effect were analysed by the Mann-Whitney U test. Logistic regression was used to test the association between the presence of a local anaesthetic action and other confounding variables.

\section{Results}

DEMONSTRATION OF A LOCAL ANAESTHETIC ACTION

After 30 minutes, 23 of $36(64 \%)$ babies showed evidence of local anaesthetic action on the amethocaine treated foot (amethocaine responders) compared with six of 36 (17\%) on the placebo treated foot (placebo responders) and seven of $36(19 \%)$ who showed no difference between feet (non-responders) (difference between amethocaine responders and the rest, $\mathrm{p}<0.001$ ) (table 2). After 60 minutes, 26 of $36(72 \%)$ babies were amethocaine responders compared with eight of $36(22 \%)$ placebo responders and two of $36(6 \%)$ non-responders (difference between amethocaine responders and the rest, $\mathrm{p}<0.001$ ).

Amethocaine responders differed from placebo responders. After 30 minutes, the median difference in grade of filament thickness was 3 in the amethocaine responders and 2 in the placebo responders $(\mathrm{p}<0.001)$. After $60 \mathrm{~min}-$ utes, the median difference was 4 in amethocaine responders and 2 in placebo responders $(\mathrm{p}<0.001)$. We compared the strength of local anaesthetic action in the two groups by recording the difference in corresponding deforming weight required to elicit the reflex between feet. After 30 minutes, the median weight difference was $21.0 \mathrm{~g}$ (interquartile range (IQR) 8.652.5) in amethocaine responders and $7.5 \mathrm{~g}$ 


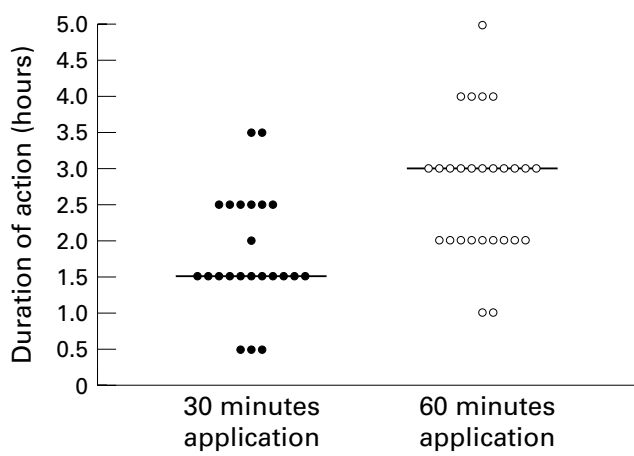

Figure 1 Duration of action of topical amethocaine gel after 30 and 60 minutes application. Horizontal bars represent median values.

(IQR 3.6-10.4) in placebo responders. This threefold difference was significant $(p=0.02)$. After 60 minutes, the median weight difference was $30.53 \mathrm{~g}$ (IQR 12.5-54.5) in amethocaine responders and $12.3 \mathrm{~g}$ (IQR 4.3-39.7) in placebo responders. This 2.5 -fold difference was not significant $(p=0.110)$. There was no statistical difference in the strength of response in the amethocaine responders at 30 and 60 minutes.

Logistic regression analysis showed that gestation, sex, and order of testing with respect to left or right foot and with respect to drug or placebo had no significant influence on the demonstration of an amethocaine or a placebo response.

DURATION OF EFFECT

The median duration of action in the amethocaine responders after 60 minutes application was three hours (range 1-5), and after $30 \mathrm{~min}-$ utes application it was 1.5 hours (range $0.5-3.5$ ) (fig 1). This difference is significant $(\mathrm{p}=0.001)$.

No local reactions were seen to the application of either amethocaine or placebo gel.

\section{Discussion}

Invasive procedures that pierce the skin of the newborn are very common. Capillary heel prick blood sampling is the most frequently performed painful procedure on the newborn intensive care unit ${ }^{1}$ and the postnatal ward. It is probably more painful than venepuncture, the next most frequently performed procedure. ${ }^{2}{ }^{3}$ The use of a lignocaine/prilocaine cream (EMLA) to relieve the pain from such procedures has been very successful in children, particularly with venepuncture. However, its use in the newborn has been less successful, with no effect on the pain of heel pricks $^{89}$ and no or limited effect on the pain of venepuncture. ${ }^{10-12}$

Amethocaine as a $4 \%(\mathrm{w} / \mathrm{w})$ gel (Ametop) has been developed for use as a topical local anaesthetic by McCafferty et al. ${ }^{18}$ It is licensed for use in term infants over 1 month of age. Structurally it has a lipophilic benzene ring attached to a tertiary amine group by an ester link chain. This differs from local anaesthetics such as lignocaine and prilocaine which have an amide link chain. It acts by blocking the influx of sodium ions across the axon and thus the propagation of the action potential along the nerve and is rapidly metabolised in the blood by plasma pseudocholinesterase. In vivo studies in adults have shown that the pain response to insertion of a needle is reduced by topical amethocaine. ${ }^{18}$ In a large study in children, application of topical amethocaine gel produced effective local anaesthesia for venepuncture in $89 \% .^{13}$ Transient localised erythema occurred in $6.3 \%$ and a localised urticarial reaction in $0.6 \%$. The plasma concentration of amethocaine and its metabolites has been studied and was found to be unrecordable in seven of 10 subjects. In those in whom amethocaine was detected, no significant side effects were reported. ${ }^{19}$ Since this time, more than 130000 applications of amethocaine have been used in over 25000 children with no serious adverse effects. ${ }^{20}$ There are few data about the use of amethocaine in the newborn. In a pilot study of 20 healthy preterm infants using $1 \%$ amethocaine ointment, Barker and Rutter ${ }^{21}$ found some evidence of percutaneous absorption with an increase in local skin blood flow, but local anaesthetic action was not assessed. This vasodilator action of amethocaine may be a practical advantage over the vasoconstrictor effect of lignocaine and prilocaine during blood sampling.

This study has confirmed our earlier work which showed that topical amethocaine gel has a local anaesthetic action in the newborn. ${ }^{17} \mathrm{At}$ 30 and 60 minutes, $64 \%$ and $72 \%$ of infants showed a local anaesthetic response to amethocaine gel. The rate of local anaesthetic response was not significantly higher after 60 minutes application. Our "placebo responders" were in effect non-responders and probably represent the variation in response that would be expected in a biological study that uses the eliciting of a reflex as an end point. Why is the rate not higher? In clinical studies of topical local anaesthesia in children, higher success rates of around $85 \%$ can be achieved, although there is always a small proportion of non-responders. There are three possible explanations. Absorption of amethocaine from the dorsum of the foot in the newborn may be very slow, so that application for a longer period is necessary to achieve positive response rates of $85 \%$. We did not test this, but the fact that the duration of response was greater after a longer period of application would support this explanation. However, the skin at this site has physiological properties that are similar to those at other sites. ${ }^{22}$ Secondly it is possible that in some newborn infants, amethocaine has no local anaesthetic action. This seems unlikely as injected local anaesthetics are invariably effective. Finally, the method of testing may lack the sensitivity needed to detect local anaesthesia. The flexor withdrawal response in the newborn has been extensively studied and shown to be both sensitive and reproducible. There is uncertainty whether the afferent pathway of the reflex is by means of fibres that transmit pain or touch, but in the context of a local anaesthetic that should inhibit all local sensation this is not relevant. The cutaneous withdrawal reflex is a 
convenient objective way of testing local anaesthetic action in the newborn without inflicting pain. $^{723-25}$ To minimise the known influence of habituation to the stimulus, we randomised the order of stimulation of the feet with respect to right or left and whether the amethocaine or placebo treated foot was tested first.

Our original study of amethocaine showed that it was effective after application for 60 minutes. There is evidence that an application time of 30 minutes can provide satisfactory anaesthesia in up to $71 \%$ of children. ${ }^{13}{ }^{18}$ We have shown that $64 \%$ of newborn infants show a positive response to amethocaine after 30 minutes. Although the response rate was not significantly longer after 60 minutes application, the duration of effect was. The median duration of action was three hours, twice as long as after 30 minutes application. This suggests that there is some choice if topical amethocaine is to be used in this age group, depending on whether speed of onset or duration of effect are needed.

We conclude that topical amethocaine gel has a local anaesthetic action when applied to the dorsum of the foot in the newborn infant. The effect after 30 and 60 minutes application is similar in terms of rate of local anaesthetic action and strength. Application for 60 minutes results in a duration of action that is twice as long. A clinical study of efficacy is now justified.

This study was entirely funded by the Higher Education Funding Council. We would like to acknowledge the help of Dr Dermot McCafferty, Department of Pharmacy, Queen's University, Belfast, who provided us with the placebo, and Sarah Pacey and Sarah Charlesworth from Nottingham City Hospital Pharmacy, who prepared the tubes and coded them.

1 Barker DP, Rutter N. Exposure to invasive procedures in neonatal intensive care unit admissions. Arch Dis Child Fetal Neonatal Ed 1995;72:F47-8.

2 Larsson BA, Tannfeldt G, Lagercrantz H, Olsson GL. Venipuncture is more effective and less painful than heel lancing for blood tests in neonates. Pediatrics 1998;101:882-6.

3 Shah VS, Taddio A, Bennett S, Speidel BD. Neonatal pain response to heel stick vs venepuncture for routine blood response to heel stick vs venepuncture for routine blood sampl

4 Harpin VA, Rutter N. Making heel pricks less painful. Arch Dis Child 1983;58:226-8.

5 Haouari N, Wood C, Griffiths G, Levene M. The analgesic effect of sucrose in full term infants: a randomised 500 .
6 Carbajal R, Chauvet X, Coudererc S, Olivier-Martin M. Randomised trial of analgesic effects of sucrose, glucose, and pacifiers in term neonates. BMF 1999;319:1393-7.

7 Barker DP, Rutter N. Lignocaine ointment and local anaesthesia in preterm infants. Arch Dis Child Fetal Neonatal Ed 1995; 72:F203-4.

8 Rushforth JA, Griffiths G, Thorpe H, Levene MI. Can topical lignocaine reduce behavioural response to heel prick? Arch Dis Child Fetal Neonatal Ed 1995;72:F49-51.

9 Larsson BA, Jylli L, Lagercrantz H, Olsson GL. Does a local anaesthetic cream (EMLA) alleviate pain from heellancing in neonates? Acta Anaesthesiol Scand 1995;39:1028-31.

10 Taddio A, Ohlsson A, Einarson TR, Stevens B, Koren G. A systematic review of lidocaine-prilocaine cream (EMLA) systematic review of lidocaine-prilocaine cream (EMLA)
in the treatment of acute pain in neonates. Pediatrics 1998;101:E1.

11 Acharya AB, Bustani PC, Phillips JD, Taub NA, Beattie RM. Randomised controlled trial of eutectic mixture of local anaesthetics cream for venepuncture in healthy preterm infants. Arch Dis Child Fetal Neonatal Ed 1998;78:F138-42.

12 Larsson BA, Tannfeldt G, Lagercrantz H, Olsson GL. Alleviation of the pain of venepuncture in neonates. Acta Paediatr Scand 1998;87:774-9.

13 Woolfson AD, McCafferty DF, Boston V. Clinical experiences with a novel percutaneous amethocaine preparation: prevention of pain due to venepuncture in children. $B r f$ Clin Pharmacol 1990;30:273-9.

14 Doyle E, Freeman J, Im NT, Morton NS. An evaluation of a new self-adhesive patch preparation of amethocaine for topical anaesthesia prior to venous cannulation in children. Anaesthesia 1993;48:1050-2.

15 Lawson RA, Smart NG, Gudgeon AC, Morton NS. Evaluation of an amethocaine gel preparation for percutaneous analgesia before venous cannulation in children. $\mathrm{Br} f$ Anaesth 1995;75:282-5.

16 McCafferty DF, Woolfson AD, Handley J, Allen G. Effect of percutaneous local anaesthetics on pain reduction during pulse dye laser treatment of portwine stains. Br $\mathcal{F}$ Anaesth 1997;78:286-9

17 Jain A, Rutter N. The local anaesthetic effect of topical amethocaine gel in the newborn: a randomised controlled trial.Arch Dis Child Fetal Neonatal Ed 2000;84:F42-5.

18 McCafferty DF, Woolfson $\mathrm{AD}$, Boston V. In vivo assessment of percutaneous local anaesthetic preparations. $\mathrm{Br} f$ Anaesth 1989;62:17-21.

19 Mazumdar B, Tomlinson AA, Faulder GC. Preliminary study to assay plasma amethocaine concentrations after topical application of a new local anaesthetic cream containing amethocaine. Br f Anaesth 1991;67:432-6.

$20 \mathrm{McCafferty}$ DF, Woolfson AD. Pharmacists 'magic' gel is launched. The Pharmaceutical fournal 1996;256:219.

21 Barker DP, Rutter NR. Skin blood flow and topical local anaesthesia in preterm infants. Early Hum Dev 1996;45:163-4.

2 Rutter N, Hull D. Water loss from the skin of term and preterm babies. Arch Dis Child 1979;54:858-68

23 Andrews K, Fitzgerald M. The cutaneous withdrawal reflex in human neonates: sensitization, receptive fields, and the effects of contralateral stimulation. Pain 1994;56:95-101.

24 Fitzgerald M, Shaw A, MacIntosh N. Postnatal development of the cutaneous flexor reflex: comparative study of preterm infants and newborn rat pups. Dev Med Child Neurol 1988;30:520-6.

25 Woolf CJ, Swett JE. The cutaneous contribution to the hamstring flexor reflex in the rat: an electrophysiological and anatomical study. Brain Res 1984;303:299-312. 